\title{
Natural products and the search for novel vaccine adjuvants
}

Jose Rey-Ladino, Ph.D. ${ }^{1 \dagger}$, Allen G. Ross, M.D., Ph.D. ${ }^{1}$, Allan W. Cripps, Ph.D. ${ }^{2}$, Donald P. McManus Ph.D. ${ }^{3}$ \& Ronald Quinn, PhD ${ }^{4}$

${ }^{1}$ Griffith Health Institute, School of Public Health, Griffith University, Logan Campus, Queensland, Australia; ${ }^{2}$ Griffith Health Institute, School of Medical Sciences, Griffith University, Gold Coast Campus, Queensland, Australia; ${ }^{3}$ Queensland Institute of Medical Research, Herston, Brisbane, Australia; ${ }^{4}$ Eskitis Institute, Brisbane, Australia

†Correspondence to: Jose Rey-Ladino, Ph.D.

School of Public Health, Logan campus, Meadowbrook

Griffith University, QLD 4131, Australia

Tel: +61(0)7 33821019

Fax: +61(0)7 33821034E-mail: j.rey-ladino@griffith.edu.au 


\begin{abstract}
Vaccines that protect against intracellular infections such as malaria, Leishmania and Chlamydia require strong cellular responses based on $\mathrm{CD}^{+} \mathrm{T}$ cells and $\mathrm{CD}^{+} \mathrm{T}$ cells in addition to antibodies. Such cell-mediated responses can be potentiated with adjuvants. However very few adjuvants have been licensed for use in humans and there is an urgent need for the discovering of new non-toxic adjuvantsto enhance the development of new and more efficacious vaccines. Until recently, the mechanisms of how adjuvants work remained largely unknown, but, it is becoming clearer that many adjuvants function via host germline-encoded pattern recognition receptors (PRRs) expressed by most immune and non-immune cells. PRRs sense infection and transmit a series of signals that ultimately lead to the development of immunity. PRR mediated signaling can be harnessed to search for new vaccine adjuvants. Dendritic cells (DCs) express many PRRs and are remarkably effective at directing T cell immunity. Natural products (NPs) have been the source of many drugs and are a rich source of immune activators and/or regulators of the immune response. Here we review PRRs in the context of NPs and propose the use of DCs as biological probes to help identify novel immune type molecules and adjuvants within collections of NPs.
\end{abstract}

Keywords:

\title{
Abbreviations:
}




\section{Introduction}

Adjuvants are substances that increase or modulate the immunogenicity of an antigen while at the same time lower the concentration of antigen required for vaccination [1, 2]. As compared with whole-cell or virus-based vaccines, subunit vaccines are poorly immunogenic and require the presence of adjuvants to stimulate protective immunity [1, 3]. However, currently licensed adjuvants such as alum predominantly induce antibody responses [4]. Adjuvants that help induce T cell-mediated immunity would facilitate the design of new vaccines for infectious diseases and cancer [5]. A major advance in the understanding of how vaccine adjuvants function is the discovery that signals derived from PRRs can activate DCs so that efficient priming and activation of $\mathrm{T}$ cells can be achieved. The best example is Toll-like receptor (TLRs) family of PRRs whose ligation by microbial signatures leads almost invariably to T cell-mediated immunity in which DCs play a major role [6].

PRRs or analogues of PRRs are expressed by most living organisms across species from plants, sponges to vertebrates [7]. In mammals, signals delivered from PRRs influence antigen presenting cells, such as DCs, with respect to the strength and type of immunity that is developed against bacterial, viral or fungal infections [8]. In invertebrates PRRs also function to provide protection against a variety of infectious agents. Because of the high levels of conservation among PRRs across species, ligands activating PRRs in lower organisms may also activate PRRs in mammals where they could be employed to modulate immune function. However the natural ligands for PRRs expressed by plants, marine organisms and other biota remain undefined.

Natural products (NPs) are a primary source of many pharmaceuticals used today [9-11] and are a potential source of immune modulating compounds.. The discovery of such compounds could result in the development of new adjuvants for vaccines and drugs for the treatment of other diseases such as allergy and cancer where immune modulating therapies are needed. We envision that new functional screening procedures and the availability of pre-fractionated libraries of NPs will 
facilitate the identification of such molecules. This review briefly summarizes the current body of knowledge of PRRs in the context of immunity in vertebrates and lower organisms and proposes a new procedure to identify potential immune modulating compounds within collections of NPs.

\section{PRRs and the triggering of immunity}

For many years, the gold standard adjuvant has been complete Freud's adjuvant (CFA), an emulsion of killed mycobacterium in oil [12]. More recently, different bacteria including Mycobacterum spp, C. parvum, B. pertusis, N. meningitidis or bacterial products have been employed as vaccine adjuvants. It is clear that most adjuvant effects of CFA and these bacteria are mediated though PRRs [13]. Indeed, PRRs are host sensors that play a leading role in the activation of the immune response in vertebrates [14]. PRRs interact with highly conserved microbial structures known as pathogen associated molecular patterns (PAMPs). Following microbial recognition, PRRs transmit signals that trigger innate immunity enabling phagocytic cells, such as macrophages and neutrophils, to mediate pathogen uptake and killing [15]. This ultimately results in initiation of proinflammatory responses and induction of adaptive immunity through the activation of DCs $[16,17]$. Not all PRRs, however, are equal in terms of their ability to trigger immunity. While some PRRs such as TLRs are able to induce both $\mathrm{B}$ and $\mathrm{T}$ cell responses, other PRRs such as macrophage mannose receptor (MMR) are not competent enough to induce an adaptive immune response on their own [8]. Major families of PRRs contributing to the development of immunity are discussed below.

\section{Nucleotide oligomerization domain-like receptors (NLRs)}

NLRs are cytosolic molecules that sense the presence of intracellular PAMPs $[18,19]$. Muramyl dipeptide (MDP) is a derivative of intracellular bacterial peptidoglycan (PGN) and is recognized by nucleotide-binding oligomerization domain 1 (NOD1), a member of the NLRs. Stimulation of NOD1 by MDP drives antigen-specific immunity into a predominant Th2 polarization profile. 
Nevertheless, stimulation of NOD1 together with TLRs (see below) also triggers Th1 or Th2 or Th17 activation pathways [20] demonstrating that NLRs potentiate responses depending on signals derived from co-engaged receptors. Another member of the NLR family is the NACHT-LRRPYD-containing protein 3 (NLP3), a component of the inflammasome - a high molecular weight complex that functions as an intracellular sensor of 'danger' [21]. Activation of NLP3 by alum triggers the activation of inflammatory DCs and subsequent development of Th2 responses [22, 23]. Shellfish shell-derived Chitosan and the saponin Quil-A are also known adjuvants that activate NLP3 signalling [24]. In general, derivatives of NLP3 strongly correlate with Th2 driven antibody responses [14].

\section{C-type lectin receptors (CLRs)}

CLRs comprise a large group of heterogeneous PRRs found almost exclusively in the Metazoa [7, 25, 26]. CLRs are calcium-dependent carbohydrate-binding proteins [1, 26] that contain at least one carbohydrate recognition domain (CRD) of $~ 130$ amino acid residues in length and are highly conserved in vertebrates [27]. CLRs have quite diverse immune function. While some are involved in recognition of self and are involved in immune homeostasis others are true PRRs [26, 28, 29]. For example, Langerin is a type II transmembrane receptor expressed by Langerhan cells and functions in fungus uptake [30]. DEC-205 is a CLR that targets antigens to late endosomes or lysosomes, MHC class II rich compartments. DEC-205 expressed by a subgroup of DCs presents antigen to $\mathrm{CD}^{+} \mathrm{T}$ cells as well as to $\mathrm{CD}^{+} \mathrm{T}$ cells via cross-presentation [31]. The macrophage mannose receptor is a CLRs that function mostly in antigen uptake but can also induce Th17 or Th2 differentiation pathways [32]. DC-SIGN was identified as an adhesion molecule expressed by human DCs. Activation of DCs via DC-SIGN however triggers IL-10 production favouring a Th2 cellular immune response [33]. Dectin-1 is a CLR that recognizes $\beta$-glucans from Candida albicans and is involved in Th17 responses and defence against fungal infections [28, 34, 35]. 
RIF-I (retinoic acid-inducible gene 1)-like receptors- RLRs

RLRs are cytosolic PRRs that exclusively detect intracellular double (dsRNA) and single stranded RNA (sRNA) from viruses [14, 36, 37]. Activation of these receptors normally requires that the cell is infected and most cell types express RLRs [38]. RLRs contain CRD domains and signal through CRD-CRD interactions with induction and production of type I interferons. In addition, RLRs complement the effect of TLRs with respect to sensing intracellular viral infections [39]. In general, signals transmitted via RLRs are sufficient to induce $\mathrm{CD}^{+} \mathrm{T}$ cells responses but are insufficient to generate $\mathrm{CD} 4^{+} \mathrm{T}$ cell or B cell responses [36].

\section{Toll-like receptors (TLRs)}

TLRs are expressed by most DCs and many other immune cells such as...??. Transmembrane TLRs contain an extracellular domain with highly conserved leucine-rich repeats of $\sim 20-30$ amino acids in length recognizing conserved microbial PAMPs [40]. Transmembrane TLRs also contain a transmembrane domain and a cytoplasmic Toll/interleukin-1 receptor (TIR) domain that mediates signal transduction [41]. Presently, 15 mammalian TLRs have been described of which 10 are found in humans [7, 42]. TLR1, TLR2, TLR4, TLR5, TLR6, TLR10, and TLR11 are expressed on the cell surface whereas TLR3, TLR7, TLR8 and TLT9 are expressed intracellulary in endosomes. Moreover, TLR2 forms heterodimers with either TLR1 or TLR6 [42].

Following microbial recognition, TLRs dimerize triggering a signalling pathway in which MyD88 adaptor protein plays a major role. This pathway ultimately leads to NF- $\kappa \mathrm{B}$ activation resulting in up-regulation of various pro-inflammatory mediators by DCs [43, 44]. Studies in mice have demonstrated that signalling though TLRs is sufficient to orchestrate an adaptive immune response, characterized by Th1 induction [45], antibody production [46] and control of adaptive immune responses [47]. 
Natural or artificial ligands for most TLRs have been identified and presently are putative immunotherapeutics and/or candidate vaccine adjuvants. An example is the modified bacterial lipopolysaccharide monophosphoryl lipid A (MPL), a TLR4 ligand, that has been licensed for use with human hepatitis B virus (HBV) and human papiloma virus (HPV) vaccines [48]. Similarly polyinosinic:polycytidylic acid (poly I:C), a TLR3 ligand, is employed in vaccines against influenza virus [49]. The unmethylated oligonucleotyde CpG (CpG), a TLR9 ligand, has been utilized in experimental vaccines against Salmonella Typhimurium [50], Toxoplasma gondii [51], Leishmania major [52] and is currently in clinical trials against cancer in humans [53]. CpG alone or a mixture of CpG and allergen is also being used in the treatment of asthma and allergies also in humans [54].

\section{PRRs trigger defence mechanisms in invertebrates and plants}

Nucleotide oligomerization domain-like receptors (NLRs)

Recent genetic analysis suggests that NLRs are important receptors involved in host defence in both invertebrates and plants. The first evolutionary conserved NLR-like proteins, in invertebrates, have been identified in the sea urchin with $\sim 203$ genes [21, 55]. The majority of these genes are expressed in cells lining the gut suggesting that the gut flora is the major driving force of NLR-like genes in the sea urchin [55]. In plants over 40 disease resistance NLR-like genes have been described [56]. In Arabidopsis nearly 170 nucleotide binding site-leucine rich repeat (NBS-LRR) encoding genes were identified [57]. These receptors play a critical role in defence against bacteria, fungi and virus infections but the specific defence mechanisms are not fully understood. Interestingly, genetic analysis has not found evolutionary link between mammalian NLRs and plant NBS-LRR suggesting that in mammals and in plants these receptors evolved separately [57].

C-type lectin receptors (CLRs) 
CLRs are abundant in invertebrates with a total of 17 gene groups [58] represented in insects, scallops [59] and nematodes [60]. The Caenorhabditis elegans genome contains approximately 278 CLR genes [60]. Invertebrate CLRs are involved in self recognition and defence, sensing specific microbial carbohydrate moieties [26]. For example, shrimp CLRs bind microbial polysaccharides on Gram negative bacteria causing bacterial agglutination [61]. Invertebrate CLRs appear to play a role in signalling cascades linked to the host immune response. In C. elegans, for example, CLR members trigger signalling pathways that activate mitogen-activated protein kinase following recognition of bacteria [62].

\section{Toll-like receptors (TLRs)}

TLRs were first described as type I transmembrane receptors that control dorsoventral patterning in Drosophila [7]. This pathway also activates signaling cascades in Drosophila closely resembling mammalian TLR signaling. Following fungal or Gram-positive bacterial infection TLR activation pathways are triggered suggesting a role in host defence [7]. The sea urchin contains 222 TLR genes with structure similar to vertebrate TLRs, many of which are encoded in tandem arrays, suggesting that a large recognition capacity is possible, via TLRs. [55]. An LPS-interacting protein (SLIP) coupled to D88 activation pathway is present in sponges [63]. Additional TLR analogues have also been recently described in the aquiferous canal system of sponges [64]. In C. elegans a single TLR homologue termed Tol-1 that has functions in the worm development as well as pathogen recognition and host defence has been identified [65]. An analogous TLR-like antimicrobial recognition system, termed TIR-NBS-LRR, is present in plants. RPSA4, a member of the TIR-NBS-LRR, was found to confer resistance to Arabidopsis against bacterial strains of Pseudomonas syringae [66]. Another receptor, the flagellin-sensitive receptor (FLS2), involved in resistance against bacterial infection was described in Arabidopsis [67]. 


\section{NPs as source of immune active compounds}

Plants. Plants are known to possessin substances that stimulate or regulate immunity. The anticancer effect of juzen-taiho-to, a popular herbal medicine used in Japan, is mediated through induction of antigen-specific anti-tumor cytotoxic $\mathrm{T}$ lymphocytes in the mouse [68]. Green tea extracts can influence resolution of pulmonary inflammation in mice. This effect is mediated through epigallocatechin-3-gallate (EGCG), a green tea component that represses the activity of reactive oxygen species and inhibits chemokine-induced neutrophil chemotaxis [69]. In addition EGCG prevents carcinogenesis in mice via a mechanism mediated by IL-12 production [70]. Another plant component, taxol from Taxus brevifilia, is an alkaloid recognized by human TLR4. Taxol inhibits cancer cell growth and is currently employed in the treatment of various cancer types such as ..... [71-73]. NP extracts have also been reported to inhibit allergic responses without suppressing protective antimicrobial immunity indicating that NPs are able to modulate immune function through inductive and suppressive mechanisms [74].

More recently, plant extracts have been examined as potential vaccine adjuvants. Extracts from Panax ginseng, an herb that possess stimulating effects, administered with ovalbumin (OVA) was found to up-regulate both Th1 and Th2 as well as antibody responses against OVA in mice [75]. Similarly, extracts from Coriolus versicolor or Astragalus memebranaceus have been found recently to induce antibody responses to cancer antigens Globo $\mathrm{H}$ and GD3 following vaccination of mice [76]. The components and mechanism(s) of immune activation of these extracts however remains unknown. However, it might be speculated that molecules within these extracts can modulate immunity by activating immune cells via PRRs.

Marine organisms. Because the marine milieu is rich in microorganisms, marine fauna can be a vast source of compounds that modulate immune function. Sponges in particular are continually exposed to many forms of bacteria during their filter feeding process. Alpha-Galactosylceramide (GalCer), 
a glycosphingolipid extracted from marine sponges, has shown to induce natural killer T cells, B cells and classical $\mathrm{T}$ cell. In the mouse, GalCer induces $\mathrm{T}$ cell and antibody responses against viral infections [77]. Sponges and the sea urchin have various PRRs analogues recognizing microbial components and involved in antimicrobial defence [55, 64]. Interesting, a novel protein complex that binds bacteria has been described in the sea urchin [78]. The natural or microbial PAMPs associated with triggering these and other PRRs in the sea urchin and sponges remain undefined.

Microorganisms. Microbes have been the primary source of PAMPs due to their role in causing infection. PRRs ligands such as bacterial peptidoglycans, fungal $\beta$-glucans, lipopolysaccaride (LPS), lipoteichoic acid, CpG, double and single stranded RNA, flagellin and others microbial PAMPs are primarily of microbial origin [79]. Most of these molecules were identified based on their ability to trigger activation of mammalian immune cells such as DCs [79]. A significant advance in understanding the role of many PAMPs is the finding that by triggering activation of DCs, these agonists and their coupling PRRs can influence the type and quality of the immune response [80]. It is notable that a number of PAMPs, including CpG and flagellin are immunostimulatory in fish [7]. This conservation of function, in mammals and in fish, suggests that there is little mutation or variation among PAMPS and raises the possibility that PAMPs derived from various biota can be used to modulate immunity in mammals. Since PRRs are evolutionary conserved across species, identification of their ligands from lower organisms will have applications in the development of new pharmaceuticals.

\section{High throughput screening (HTS) of immune compounds}

NPs include small molecules that have been evolutionary selected to bind protein domains [81]. Binding of NPs to their domains is selective and of high affinity [82]. If these compounds comply 
with the established drug-like/lead-like criteria, summarized in the Lipinski's "rule of five", they become favourable lead structures for drug discovery [83, 84].

Natural product libraries (NPLs) have been essential in HTS and identification of new drugs or product leads and many of these compound libraries have been developed over the past few years [83, 85]. More specialized compound libraries have been developed based on the concept of protein structure similarity clusters (PSSC) that searches for small molecule activators/modulators of protein function. Central for this design is the criteria of product diversity, drug-likeness and biological relevance [81]. Modern NPLs are pre-fractionated and individual fractions contain only a few compounds whose molecular structure can be easily identified following screening [86].

Screening for NPs with immune stimulating properties has not been routinely established for HTS and product discovery. Interesting, immune molecules derived form NPs may comply with the drug-like/lead-like criteria and the Lipinski "rule of five” established for classical NPs-derived drugs. A chemical library of 24,000 compounds was recently screened with TLR2 proteins and various TLR2-dependent activators were identified. These compounds were of low molecular mass (less than 500 daltons), bound to localized regions within the TLR2 extracellular domain and activated murine and human macrophages [87]. TLR activation occurs when their ligand(s) bind extracellular domain pockets of the TLR protein causing TLR dimerization. This assembly serves as a platform for the recruitment of adaptor molecules required to initiate signalling [88]. Together, this suggests that structure and function of ligands modulating/activating within NPs may have lots in common to drugs derived from NPs. HTS based on NPs can identify products or product leads that modulate immunity. These substances may be employed to prevent or treat infections, cancer and autoimmune diseases from the perspective of host immunity.

\section{Dendritic cells (DCs)}


Dendritic cell maturation. DC subsets direct the differentiation of $\mathrm{CD}^{+} \mathrm{T}$ cells into IFN- $\gamma$ producing Th1 cells [89]. Depending on their state of maturation, DCs also govern the differentiation of regulatory T cells to produce IL-10 and TGF- $\beta[3,90]$. However, to become efficient inducers of T cells DCs must differentiate from immature DCs (iDCs) into mature DCs (mDCs) [91, 92]. Maturation of DCs occurs after sensing PAMPs through PRRs, or through exposure to pro-inflammatory cytokines [91, 93]. Binding of PAMPs to TLRs on DCs results in induction of DC maturation, characterized by activation of NF-kB family of transcription factors resulting in enhanced expression of MHC class I and II, upregulation of co-stimulatory molecules and secretion of TNF- $\alpha$, IL-6, IFNs type I and type III and IL-12 [13, 94].

Tolerogenic DCs. Immature or maturation-resistant DCs (iDCs) become tolerogenic [95]. These DCs have impaired ability to synthesize Th1 type cytokines such as IL-12p70 and express low amounts of MHC and costimulatory molecules. DCs isolated from patients infected with T-cell lymphocyte virus type 1 (HTL-1) are unable to mature and this effect has been correlated with the inability of these patients to control HTL-1 infection [96]. Similarly, the Simian virus 40 (SV40) down regulates maturation of DCs resulting in impaired DC-induced T cell proliferation leading to immunosupression of individuals infected with SV40 infection [97]. Of note, tolerogenic DCs can be generated with many immune-suppressors including docosahexaenoic acid (DHA), corticosteroids, cyclosporine, tacrolimus, rapamycin, aspirin, deoxyspergualin, mycophenolate

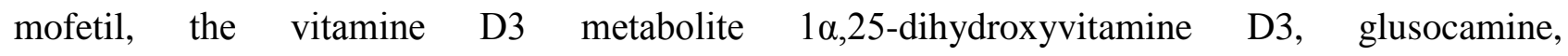
histamineprostaglandine E2 [95, 98, 99]. The majority of these agents prevent DC maturation and/or their activation impairing the ability of DCs to produce IL-12 p70 in which IL-10 and TGF- $\beta$ play a major role [95]. Therefore it is critical to ensure that DC maturation is stimulated in any attempt to induce protective immunity by targeting DCs in vivo, otherwise tolerogenic responses can be induced.. 
DCs as biological probes for HTS of NPs. The ability of DCs to initiate and regulate immunity as well as their ability to undergo maturation via PRRs can be utilized to identify new immune compounds and adjuvants. Human monocyte-derived DCs (MoDCs) and myeloid DCs express most known TLRs including TLR1, TLR2, TLR3, TLR4, TLR5, TLR6 and TLR8 [8, 42, 101]. In addition MoDC express various CLRs including the MMR and DEC205 as well as NLRs NOD1 and NOD2 [102]. Furthermore, MoDCs express numerous markers such as CD4, CD11b, CD11c, CD13, CD33, CD1a and Ly6c. Upon activation, MoDC secrete secret IL-1 $\beta$, IL-6, IL-10, bioactive IL-12p70, IL-18 and IL-23 depending on the activation status [102, 103]. MoDCs can be generated from human peripheral blood monocytes cultured in vitro with GM-CSF and IL-4 or IL-13 [104]. Murine DCs can be also generated in vitro from bone marrow cells (BM-DCs) cultured in the presence of GM-CSF and IL-4 [105]. Of note, TLR7 and TLR9 are no expressed by MoDCs but they are expressed plamacytoid DCs (pDCs), a DC subset involved in anti-virus defence. Both human and murine pDCs can be differentiated in vitro in the presence of flt3 ligand and can undergo maturation in response to PRR ligands $[8,106]$.

We propose a procedure for screening NPLs utilizing DCs as bioprobes in Figure 1. In this procedure:

(i) immature DCs are grown from human peripheral mononuclear cells or from mouse bone marrow cells,

(ii) iDCs are then incubated with pre-fractionated NPLs and the culture supernatants recovered,

(iii) The culture supernatants of treated DCs are examined for secreted cytokines,

(iv) Cytokine profiles secreted by DCs following incubation with NP fractions are utilized to classify NP fractions in Th1 or Th2, 
(v) NP fractions inducing Th1 cytokines are further tested for their ability to induce DC maturation and DC immunogenicity,

(vi) Th1 fractions are then further tested in vaccines as adjuvants in established animal models of infection.

(vii) The molecular identification of the active compound within the Th1-inducing fraction is identified by mass spectrometry using appropriate PRRs [86] and finally,.

(viii) The active compound is re-assessed in prototype vaccine formulations in established animal models of infection.

NEED TO COMMENT ON FEASIBILITY AND PRELIMINARY WORK WHICH DEMONSTRATES THE PROCEDURE WORKS!!!!

\section{Conclusions}

NPs have provided a very rich source of pharmaceuticals used in research and medicine including antibiotics, anti-tumour, anti-cholesteric and immunossupressive agents such as cyclosporine A and FK 506. NPLs remain a rich resource from which new compounds that are able to modulate immune function can be discovered. A significant field of research has now developed around NPs which has lead to development of sophisticated technologies for the identification of compounds and their analysis. However, there is a need to rapid functional screening procedures that can be assessed in relevant biological model. Pre-fractionated libraries based on NPs and established biochemical technologies offer a unique opportunity to search for these compounds. This can be readily accomplished using DCs as bioprobes and established immunological read outs.

Figure 1. A model for identification of adjuvants within collections of NPs. Endotoxin-free, fractionated library of NPs is screened with human and/or mouse DCs. NP fractions preferentially inducing Th1 cytokines such as IL-12, TNF- $\alpha$, IL-27 and expressing low levels of Th2 cytokines such IL-10 by DCs by will be tested immunologically for inducing immunogenicity of DC including maturation and antigen presentation. Fractions promoting Th1 responses will be tested in 
vaccines as adjuvants. Subsequently, the active molecules within these Th1 fractions are identified by mass spectrometry SEC-MS based on their ability to bind appropriate PRRs. The adjuvanticity of Th1 inducing molecules are tested in prophylactic vaccines in animal models of infection.

Acknowledgements

\section{References}

[1] Kwissa M, Kasturi SP, Pulendran B. The science of adjuvants. Expert Rev Vaccines 2007 Oct;6(5):673-84.

[2] Rappuoli R. Bridging the knowledge gaps in vaccine design. Nat Biotechnol 2007 Dec;25(12):1361-6.

[3] Steinman RM. Dendritic cells in vivo: a key target for a new vaccine science. Immunity 2008 Sep 19;29(3):319-24.

[4] Tritto E, Mosca F, De Gregorio E. Mechanism of action of licensed vaccine adjuvants. Vaccine 2009 May 26;27(25-26):3331-4.

[5] Guy B. The perfect mix: recent progress in adjuvant research. Nat Rev Microbiol 2007 Jul;5(7):505-17.

[6] Raman VS, Bhatia A, Picone A, Whittle J, Bailor HR, O'Donnell J, et al. Applying TLR synergy in immunotherapy: implications in cutaneous leishmaniasis. J Immunol 2010 Aug 1;185(3):1701-10.

[7] Akira S, Uematsu S, Takeuchi O. Pathogen recognition and innate immunity. Cell 2006 Feb 24;124(4):783-801.

[8] Iwasaki A, Medzhitov R. Toll-like receptor control of the adaptive immune responses. Nat Immunol 2004 Oct;5(10):987-95.

[9] Cragg GM, Grothaus PG, Newman DJ. Impact of natural products on developing new anticancer agents. Chem Rev 2009 Jul;109(7):3012-43.

[10] Lam KS. New aspects of natural products in drug discovery. Trends Microbiol 2007 Jun;15(6):279-89.

[11] Newman DJ, Cragg GM. Natural products as sources of new drugs over the last 25 years. J Nat Prod 2007 Mar;70(3):461-77.

[12] Billiau A, Matthys P. Modes of action of Freund's adjuvants in experimental models of autoimmune diseases. J Leukoc Biol 2001 Dec;70(6):849-60.

[13] Medzhitov R. Toll-like receptors and innate immunity. Nat Rev Immunol 2001 Nov;1(2):135-45.

[14] Palm NW, Medzhitov R. Pattern recognition receptors and control of adaptive immunity. Immunol Rev 2009 Jan;227(1):221-33.

[15] Janeway CA, Jr. Approaching the asymptote? Evolution and revolution in immunology. Cold Spring Harb Symp Quant Biol 1989;54 Pt 1:1-13.

[16] Monie TP, Bryant CE, Gay NJ. Activating immunity: lessons from the TLRs and NLRs. Trends Biochem Sci 2009 Nov;34(11):553-61.

[17] Reis e Sousa C. Activation of dendritic cells: translating innate into adaptive immunity. Curr Opin Immunol 2004 Feb;16(1):21-5.

[18] Franchi L, Warner N, Viani K, Nunez G. Function of Nod-like receptors in microbial recognition and host defense. Immunol Rev 2009 Jan;227(1):106-28.

[19] Fritz JH, Ferrero RL, Philpott DJ, Girardin SE. Nod-like proteins in immunity, inflammation and disease. Nat Immunol 2006 Dec;7(12):1250-7. 
[20] Fritz JH, Le Bourhis L, Sellge G, Magalhaes JG, Fsihi H, Kufer TA, et al. Nod1-mediated innate immune recognition of peptidoglycan contributes to the onset of adaptive immunity. Immunity 2007 Apr;26(4):445-59.

[21] Martinon F, Mayor A, Tschopp J. The inflammasomes: guardians of the body. Annu Rev Immunol 2009;27:229-65.

[22] Kool M, Soullie T, van Nimwegen M, Willart MA, Muskens F, Jung S, et al. Alum adjuvant boosts adaptive immunity by inducing uric acid and activating inflammatory dendritic cells. $\mathrm{J}$ Exp Med 2008 Apr 14;205(4):869-82.

[23] Petrilli V, Dostert C, Muruve DA, Tschopp J. The inflammasome: a danger sensing complex triggering innate immunity. Curr Opin Immunol 2007 Dec;19(6):615-22.

[24] Li H, Willingham SB, Ting JP, Re F. Cutting edge: inflammasome activation by alum and alum's adjuvant effect are mediated by NLRP3. J Immunol 2008 Jul 1;181(1):17-21.

[25] Huysamen C, Brown GD. The fungal pattern recognition receptor, Dectin-1, and the associated cluster of C-type lectin-like receptors. FEMS Microbiol Lett 2009 Jan;290(2):121-8.

[26] Robinson MJ, Sancho D, Slack EC, LeibundGut-Landmann S, Reis e Sousa C. Myeloid Ctype lectins in innate immunity. Nat Immunol 2006 Dec;7(12):1258-65.

[27] Drickamer K. Two distinct classes of carbohydrate-recognition domains in animal lectins. J Biol Chem 1988 Jul 15;263(20):9557-60.

[28] LeibundGut-Landmann S, Gross O, Robinson MJ, Osorio F, Slack EC, Tsoni SV, et al. Sykand CARD9-dependent coupling of innate immunity to the induction of T helper cells that produce interleukin 17. Nat Immunol 2007 Jun;8(6):630-8.

[29] Dillon S, Agrawal S, Banerjee K, Letterio J, Denning TL, Oswald-Richter K, et al. Yeast zymosan, a stimulus for TLR2 and dectin-1, induces regulatory antigen-presenting cells and immunological tolerance. J Clin Invest 2006 Apr;116(4):916-28.

[30] de Jong MA, Vriend LE, Theelen B, Taylor ME, Fluitsma D, Boekhout T, et al. C-type lectin Langerin is a beta-glucan receptor on human Langerhans cells that recognizes opportunistic and pathogenic fungi. Mol Immunol 2010 Mar;47(6):1216-25.

[31] Dudziak D, Kamphorst AO, Heidkamp GF, Buchholz VR, Trumpfheller C, Yamazaki S, et al. Differential antigen processing by dendritic cell subsets in vivo. Science 2007 Jan 5;315(5808):107-11.

[32] van de Veerdonk FL, Marijnissen RJ, Kullberg BJ, Koenen HJ, Cheng SC, Joosten I, et al. The macrophage mannose receptor induces IL-17 in response to Candida albicans. Cell Host Microbe 2009 Apr 23;5(4):329-40.

[33] Caparros E, Munoz P, Sierra-Filardi E, Serrano-Gomez D, Puig-Kroger A, RodriguezFernandez JL, et al. DC-SIGN ligation on dendritic cells results in ERK and PI3K activation and modulates cytokine production. Blood 2006 May 15;107(10):3950-8.

[34] Taylor PR, Tsoni SV, Willment JA, Dennehy KM, Rosas M, Findon H, et al. Dectin-1 is required for beta-glucan recognition and control of fungal infection. Nat Immunol 2007 Jan;8(1):31-8.

[35] Weaver CT, Hatton RD, Mangan PR, Harrington LE. IL-17 family cytokines and the expanding diversity of effector T cell lineages. Annu Rev Immunol 2007;25:821-52.

[36] Koyama S, Ishii KJ, Kumar H, Tanimoto T, Coban C, Uematsu S, et al. Differential role of TLR- and RLR-signaling in the immune responses to influenza A virus infection and vaccination. J Immunol 2007 Oct 1;179(7):4711-20.

[37] Pichlmair A, Schulz O, Tan CP, Naslund TI, Liljestrom P, Weber F, et al. RIG-I-mediated antiviral responses to single-stranded RNA bearing 5'-phosphates. Science 2006 Nov 10;314(5801):997-1001.

[38] Iwasaki A, Medzhitov R. Regulation of adaptive immunity by the innate immune system. Science 2010 Jan 15;327(5963):291-5. 
[39] Kawai T, Takahashi K, Sato S, Coban C, Kumar H, Kato H, et al. IPS-1, an adaptor triggering RIG-I- and Mda5-mediated type I interferon induction. Nat Immunol 2005 Oct;6(10):981-8.

[40] Gay NJ, Gangloff M. Structure and function of Toll receptors and their ligands. Annu Rev Biochem 2007;76:141-65.

[41] Bell JK, Mullen GE, Leifer CA, Mazzoni A, Davies DR, Segal DM. Leucine-rich repeats and pathogen recognition in Toll-like receptors. Trends Immunol 2003 Oct;24(10):528-33.

[42] Schreibelt G, Tel J, Sliepen KH, Benitez-Ribas D, Figdor CG, Adema GJ, et al. Toll-like receptor expression and function in human dendritic cell subsets: implications for dendritic cellbased anti-cancer immunotherapy. Cancer Immunol Immunother 2010 Oct;59(10):1573-82.

[43] van Duin D, Medzhitov R, Shaw AC. Triggering TLR signaling in vaccination. Trends Immunol 2006 Jan;27(1):49-55.

[44] Jankovic D, Kullberg MC, Hieny S, Caspar P, Collazo CM, Sher A. In the absence of IL-12, CD4(+) $\mathrm{T}$ cell responses to intracellular pathogens fail to default to a Th2 pattern and are host protective in an IL-10(-/-) setting. Immunity 2002 Mar;16(3):429-39.

[45] Pasare C, Medzhitov R. Toll-dependent control mechanisms of CD4 T cell activation. Immunity 2004 Nov;21(5):733-41.

[46] Pasare C, Medzhitov R. Control of B-cell responses by Toll-like receptors. Nature 2005 Nov 17;438(7066):364-8.

[47] Schnare M, Barton GM, Holt AC, Takeda K, Akira S, Medzhitov R. Toll-like receptors control activation of adaptive immune responses. Nat Immunol 2001 Oct;2(10):947-50.

[48] Garcon N, Chomez P, Van Mechelen M. GlaxoSmithKline Adjuvant Systems in vaccines: concepts, achievements and perspectives. Expert Rev Vaccines 2007 Oct;6(5):723-39.

[49] Ichinohe T, Watanabe I, Ito S, Fujii H, Moriyama M, Tamura S, et al. Synthetic doublestranded RNA poly(I:C) combined with mucosal vaccine protects against influenza virus infection. J Virol 2005 Mar;79(5):2910-9.

[50] Berchtold C, Panthel K, Jellbauer S, Kohn B, Roider E, Partilla M, et al. Superior protective immunity against murine listeriosis by combined vaccination with CpG DNA and recombinant Salmonella enterica serovar typhimurium. Infect Immun 2009 Dec;77(12):5501-8.

[51] El-Malky M, Shaohong L, Kumagai T, Yabu Y, Noureldin MS, Saudy N, et al. Protective effect of vaccination with Toxoplasma lysate antigen and $\mathrm{CpG}$ as an adjuvant against Toxoplasma gondii in susceptible C57BL/6 mice. Microbiol Immunol 2005;49(7):639-46.

[52] Rhee EG, Mendez S, Shah JA, Wu CY, Kirman JR, Turon TN, et al. Vaccination with heatkilled leishmania antigen or recombinant leishmanial protein and $\mathrm{CpG}$ oligodeoxynucleotides induces long-term memory CD4+ and CD8+ T cell responses and protection against leishmania major infection. J Exp Med 2002 Jun 17;195(12):1565-73.

[53] Kim YH, Girardi M, Duvic M, Kuzel T, Link BK, Pinter-Brown L, et al. Phase I trial of a Toll-like receptor 9 agonist, PF-3512676 (CPG 7909), in patients with treatment-refractory, cutaneous T-cell lymphoma. J Am Acad Dermatol 2010 Dec;63(6):975-83.

[54] Gupta GK, Agrawal DK. CpG oligodeoxynucleotides as TLR9 agonists: therapeutic application in allergy and asthma. BioDrugs 2010 Aug 1;24(4):225-35.

[55] Hibino T, Loza-Coll M, Messier C, Majeske AJ, Cohen AH, Terwilliger DP, et al. The immune gene repertoire encoded in the purple sea urchin genome. Dev Biol 2006 Dec 1;300(1):349-65.

[56] Hammond-Kosack KE, Jones JD. Plant Disease Resistance Genes. Annu Rev Plant Physiol Plant Mol Biol 1997 Jun;48:575-607.

[57] Tan X, Meyers BC, Kozik A, West MA, Morgante M, St Clair DA, et al. Global expression analysis of nucleotide binding site-leucine rich repeat-encoding and related genes in Arabidopsis. BMC Plant Biol 2007;7:56. 
[58] Zelensky AN, Gready JE. The C-type lectin-like domain superfamily. FEBS J 2005 Dec;272(24):6179-217.

[59] Zhang H, Wang H, Wang L, Song L, Song X, Zhao J, et al. Cflec-4, a multidomain C-type lectin involved in immune defense of Zhikong scallop Chlamys farreri. Dev Comp Immunol 2009 Jun;33(6):780-8.

[60] Schulenburg H, Hoeppner MP, Weiner J, 3rd, Bornberg-Bauer E. Specificity of the innate immune system and diversity of C-type lectin domain (CTLD) proteins in the nematode Caenorhabditis elegans. Immunobiology 2008;213(3-4):237-50.

[61] Xu WT, Wang XW, Zhang XW, Zhao XF, Yu XQ, Wang JX. A new C-type lectin (FcLec5) from the Chinese white shrimp Fenneropenaeus chinensis. Amino Acids 2010 Nov;39(5):1227-39.

[62] Huffman DL, Abrami L, Sasik R, Corbeil J, van der Goot FG, Aroian RV. Mitogenactivated protein kinase pathways defend against bacterial pore-forming toxins. Proc Natl Acad Sci U S A 2004 Jul 27;101(30):10995-1000.

[63] Wiens M, Korzhev M, Krasko A, Thakur NL, Perovic-Ottstadt S, Breter HJ, et al. Innate immune defense of the sponge Suberites domuncula against bacteria involves a MyD88-dependent signaling pathway. Induction of a perforin-like molecule. J Biol Chem 2005 Jul 29;280(30):2794959.

[64] Wiens M, Korzhev M, Perovic-Ottstadt S, Luthringer B, Brandt D, Klein S, et al. Toll-like receptors are part of the innate immune defense system of sponges (demospongiae: Porifera). Mol Biol Evol 2007 Mar;24(3):792-804.

[65] Pujol N, Link EM, Liu LX, Kurz CL, Alloing G, Tan MW, et al. A reverse genetic analysis of components of the Toll signaling pathway in Caenorhabditis elegans. Curr Biol 2001 Jun 5;11(11):809-21.

[66] Gassmann W, Hinsch ME, Staskawicz BJ. The Arabidopsis RPS4 bacterial-resistance gene is a member of the TIR-NBS-LRR family of disease-resistance genes. Plant J 1999 Nov;20(3):26577.

[67] Gomez-Gomez L, Boller T. FLS2: an LRR receptor-like kinase involved in the perception of the bacterial elicitor flagellin in Arabidopsis. Mol Cell 2000 Jun;5(6):1003-11.

[68] Dai Y, Kato M, Takeda K, Kawamoto Y, Akhand AA, Hossain K, et al. T-cell-immunitybased inhibitory effects of orally administered herbal medicine juzen-taiho-to on the growth of primarily developed melanocytic tumors in RET-transgenic mice. J Invest Dermatol 2001 Sep;117(3):694-701.

[69] Dona M, Dell'Aica I, Calabrese F, Benelli R, Morini M, Albini A, et al. Neutrophil restraint by green tea: inhibition of inflammation, associated angiogenesis, and pulmonary fibrosis. J Immunol 2003 Apr 15;170(8):4335-41.

[70] Meeran SM, Mantena SK, Elmets CA, Katiyar SK. (-)-Epigallocatechin-3-gallate prevents photocarcinogenesis in mice through interleukin-12-dependent DNA repair. Cancer Res 2006 May 15;66(10):5512-20.

[71] Rivera E, Gomez H. Chemotherapy resistance in metastatic breast cancer: the evolving role of ixabepilone. Breast Cancer Res;12 Suppl 2:S2.

[72] Saville MW, Lietzau J, Pluda JM, Feuerstein I, Odom J, Wilson WH, et al. Treatment of HIV-associated Kaposi's sarcoma with paclitaxel. Lancet 1995 Jul 1;346(8966):26-8.

[73] Szajnik M, Szczepanski MJ, Czystowska M, Elishaev E, Mandapathil M, Nowak-Markwitz E, et al. TLR4 signaling induced by lipopolysaccharide or paclitaxel regulates tumor survival and chemoresistance in ovarian cancer. Oncogene 2009 Dec 10;28(49):4353-63.

[74] Li XM, Huang CK, Zhang TF, Teper AA, Srivastava K, Schofield BH, et al. The chinese herbal medicine formula MSSM-002 suppresses allergic airway hyperreactivity and modulates TH1/TH2 responses in a murine model of allergic asthma. J Allergy Clin Immunol 2000 Oct;106(4):660-8. 
[75] Song X, Zang L, Hu S. Amplified immune response by ginsenoside-based nanoparticles (ginsomes). Vaccine 2009 Apr 14;27(17):2306-11.

[76] Ragupathi G, Yeung KS, Leung PC, Lee M, Lau CB, Vickers A, et al. Evaluation of widely consumed botanicals as immunological adjuvants. Vaccine 2008 Sep 2;26(37):4860-5.

[77] Lindqvist M, Persson J, Thorn K, Harandi AM. The mucosal adjuvant effect of alphagalactosylceramide for induction of protective immunity to sexually transmitted viral infection. J Immunol 2009 May 15;182(10):6435-43.

[78] Ghosh J, Buckley KM, Nair SV, Raftos DA, Miller C, Majeske AJ, et al. Sp185/333: a novel family of genes and proteins involved in the purple sea urchin immune response. Dev Comp Immunol 2010 Mar;34(3):235-45.

[79] Akira S. Pathogen recognition by innate immunity and its signaling. Proc Jpn Acad Ser B Phys Biol Sci 2009;85(4):143-56.

[80] Kaisho T, Akira S. Toll-like receptors as adjuvant receptors. Biochim Biophys Acta 2002 Feb 13;1589(1):1-13.

[81] Koch MA, Waldmann H. Protein structure similarity clustering and natural product structure as guiding principles in drug discovery. Drug Discov Today 2005 Apr 1;10(7):471-83.

[82] Feher M, Schmidt JM. Property distributions: differences between drugs, natural products, and molecules from combinatorial chemistry. J Chem Inf Comput Sci 2003 Jan-Feb;43(1):218-27.

[83] Quinn RJ, Carroll AR, Pham NB, Baron P, Palframan ME, Suraweera L, et al. Developing a drug-like natural product library. J Nat Prod 2008 Mar;71(3):464-8.

[84] Koehn FE, Carter GT. The evolving role of natural products in drug discovery. Nat Rev Drug Discov 2005 Mar;4(3):206-20.

[85] Bugni TS, Richards B, Bhoite L, Cimbora D, Harper MK, Ireland CM. Marine natural product libraries for high-throughput screening and rapid drug discovery. J Nat Prod 2008 Jun;71(6):1095-8.

[86] $\mathrm{Vu} \mathrm{H}$, Pham NB, Quinn RJ. Direct screening of natural product extracts using mass spectrometry. J Biomol Screen 2008 Apr;13(4):265-75.

[87] Guan Y, Omueti-Ayoade K, Mutha SK, Hergenrother PJ, Tapping RI. Identification of novel synthetic toll-like receptor 2 agonists by high throughput screening. J Biol Chem Jul 30;285(31):23755-62.

[88] O'Neill LA, Bowie AG. The family of five: TIR-domain-containing adaptors in Toll-like receptor signalling. Nat Rev Immunol 2007 May;7(5):353-64.

[89] Banchereau J, Steinman RM. Dendritic cells and the control of immunity. Nature 1998 Mar 19;392(6673):245-52.

[90] Hawrylowicz CM. Regulatory T cells and IL-10 in allergic inflammation. J Exp Med 2005 Dec 5;202(11):1459-63.

[91] Steinman RM, Pope M. Exploiting dendritic cells to improve vaccine efficacy. J Clin Invest 2002 Jun;109(12):1519-26.

[92] de Vries IJ, Lesterhuis WJ, Scharenborg NM, Engelen LP, Ruiter DJ, Gerritsen MJ, et al. Maturation of dendritic cells is a prerequisite for inducing immune responses in advanced melanoma patients. Clin Cancer Res 2003 Nov 1;9(14):5091-100.

[93] van den Broek M. Dendritic cells break bonds to tolerize. Immunity 2007 Oct;27(4):544-6.

[94] Gautier G, Humbert M, Deauvieau F, Scuiller M, Hiscott J, Bates EE, et al. A type I interferon autocrine-paracrine loop is involved in Toll-like receptor-induced interleukin-12p70 secretion by dendritic cells. J Exp Med 2005 May 2;201(9):1435-46.

[95] Morelli AE, Thomson AW. Tolerogenic dendritic cells and the quest for transplant tolerance. Nat Rev Immunol 2007 Aug;7(8):610-21.

[96] Nascimento CR, Lima MA, de Andrada Serpa MJ, Espindola O, Leite AC, Echevarria-Lima J. Monocytes from HTLV-1-infected patients are unable to fully mature into dendritic cells. Blood Jan 13;117(2):489-99. 
[97] Changyong C, Sun M, Li H, Brockmeyer N, Wu NP. Simian virus 40 inhibits differentiation and maturation of rhesus macaque DC-SIGN(+) dendritic cells. Eur J Med Res Sep 24;15(9):37782.

[98] Unger WW, Laban S, Kleijwegt FS, van der Slik AR, Roep BO. Induction of Treg by monocyte-derived DC modulated by vitamin D3 or dexamethasone: differential role for PD-L1. Eur J Immunol 2009 Nov;39(11):3147-59.

[99] Kong W, Yen JH, Vassiliou E, Adhikary S, Toscano MG, Ganea D. Docosahexaenoic acid prevents dendritic cell maturation and in vitro and in vivo expression of the IL-12 cytokine family. Lipids Health Dis 2010;9:12.

[100] Hawiger D, Inaba K, Dorsett Y, Guo M, Mahnke K, Rivera M, et al. Dendritic cells induce peripheral $\mathrm{T}$ cell unresponsiveness under steady state conditions in vivo. J Exp Med 2001 Sep 17;194(6):769-79.

[101] Jarrossay D, Napolitani G, Colonna M, Sallusto F, Lanzavecchia A. Specialization and complementarity in microbial molecule recognition by human myeloid and plasmacytoid dendritic cells. Eur J Immunol 2001 Nov;31(11):3388-93.

[102] Zhan Y, Xu Y, Seah S, Brady JL, Carrington EM, Cheers C, et al. Resident and monocytederived dendritic cells become dominant IL-12 producers under different conditions and signaling pathways. J Immunol 2010 Aug 15;185(4):2125-33.

[103] Jefford M, Schnurr M, Toy T, Masterman KA, Shin A, Beecroft T, et al. Functional comparison of DCs generated in vivo with Flt3 ligand or in vitro from blood monocytes: differential regulation of function by specific classes of physiologic stimuli. Blood 2003 Sep 1;102(5):1753-63.

[104] Sallusto F, Lanzavecchia A. Efficient presentation of soluble antigen by cultured human dendritic cells is maintained by granulocyte/macrophage colony-stimulating factor plus interleukin 4 and downregulated by tumor necrosis factor alpha. J Exp Med 1994 Apr 1;179(4):1109-18.

[105] Inaba K, Inaba M, Romani N, Aya H, Deguchi M, Ikehara S, et al. Generation of large numbers of dendritic cells from mouse bone marrow cultures supplemented with granulocyte/macrophage colony-stimulating factor. J Exp Med 1992 Dec 1;176(6):1693-702.

[106] Brawand P, Fitzpatrick DR, Greenfield BW, Brasel K, Maliszewski CR, De Smedt T. Murine plasmacytoid pre-dendritic cells generated from Flt3 ligand-supplemented bone marrow cultures are immature APCs. J Immunol 2002 Dec 15;169(12):6711-9.

Figure 1 
Fractionated

library of NPs
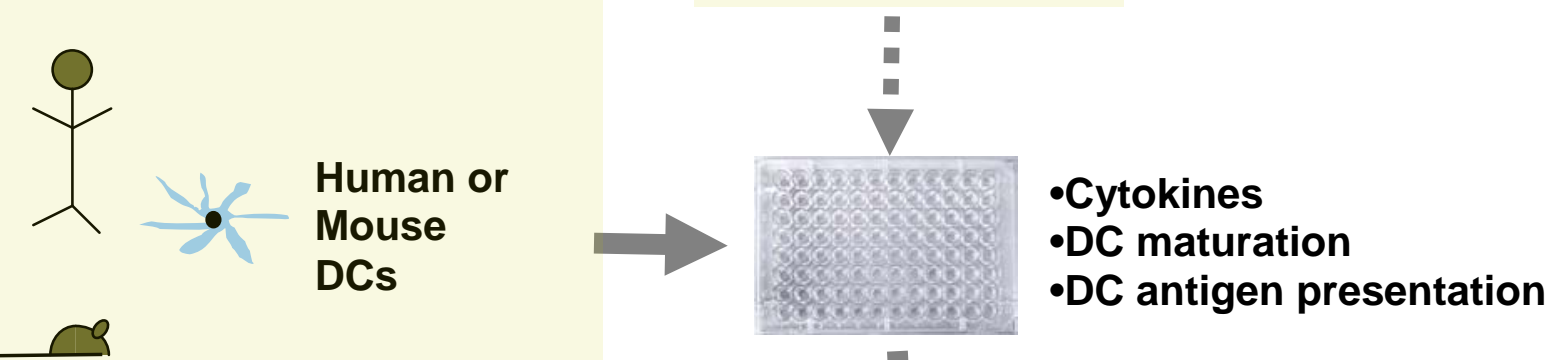

Immunizations

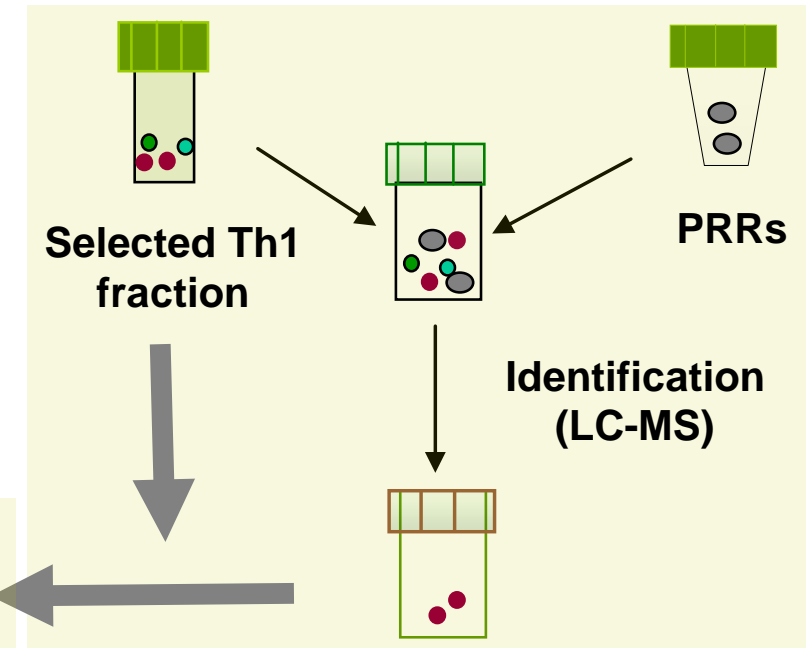

Molecular adjuvant 